\title{
A Portable System for Nuclear, Chemical Agent and Explosives Identification
}

\author{
W.E. Parker, W.M. Buckley, S.A. Kreek, A.J. Caffrey, \\ G.J. Mauger, A.D. Lavietes, A.D. Dougan
}

This article was submitted to $16^{\text {th }}$ International Conference on the Application of Accelerators in Research and Industry, Denton, TX, November 1-4, 2000

\section{September 29, 2000}

U.S. Department of Energy

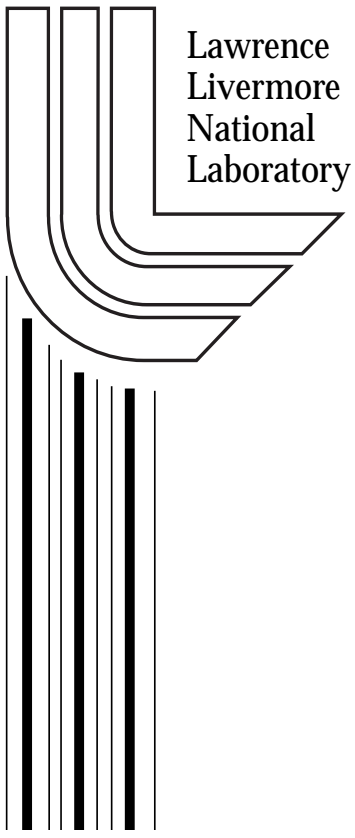




\section{DISCLAIMER}

This document was prepared as an account of work sponsored by an agency of the United States Government. Neither the United States Government nor the University of California nor any of their employees, makes any warranty, express or implied, or assumes any legal liability or responsibility for the accuracy, completeness, or usefulness of any information, apparatus, product, or process disclosed, or represents that its use would not infringe privately owned rights. Reference herein to any specific commercial product, process, or service by trade name, trademark, manufacturer, or otherwise, does not necessarily constitute or imply its endorsement, recommendation, or favoring by the United States Government or the University of California. The views and opinions of authors expressed herein do not necessarily state or reflect those of the United States Government or the University of California, and shall not be used for advertising or product endorsement purposes.

This is a preprint of a paper intended for publication in a journal or proceedings. Since changes may be made before publication, this preprint is made available with the understanding that it will not be cited or reproduced without the permission of the author.

This report has been reproduced directly from the best available copy.

Available to DOE and DOE contractors from the

Office of Scientific and Technical Information

P.O. Box 62, Oak Ridge, TN 37831

Prices available from (423) 576-8401

http:/ / apollo.osti.gov/bridge/

Available to the public from the National Technical Information Service

U.S. Department of Commerce 5285 Port Royal Rd., Springfield, VA 22161 http://www.ntis.gov/

OR

Lawrence Livermore National Laboratory Technical Information Department's Digital Library http://www.llnl.gov/tid/Library.html 


\title{
A Portable System for Nuclear, Chemical Agent and Explosives Identification
}

\author{
W. E. Parker, W.M. Buckley, ${ }^{*}$ S.A. Kreek, ${ }^{*}$ A. J. Caffrey, ${ }^{*}$ \\ G.J. Mauger, ${ }^{*}$ A. D. Lavietes, ${ }^{*}$ and A. D. Dougan* \\ *Lawrence Livermore National Laboratory, P. O. Box 808 Livermore, CA 94550 \\ ${ }^{*}$ Idaho National Engineering and Environmental Laboratory, Idaho Falls, Idaho
}

\begin{abstract}
The FRIS/PINS hybrid integrates the LLNL-developed Field Radionuclide Identification System (FRIS) with the INEEL-developed Portable Isotopic Neutron Spectroscopy (PINS) chemical assay system to yield a combined general radioisotope, special nuclear material, and chemical weapons/explosives detection and identification system. The PINS system uses a neutron source and a high-purity germanium $\gamma$-ray detector. The FRIS system uses an electromechanically cooled germanium detector and its own analysis software to detect and identify special nuclear material and other radioisotopes. The FRIS/PINS combined system also uses the electromechanically-cooled germanium detector. There is no other currently available integrated technology that can combine an active neutron interrogation and analysis capability for CWE with a passive radioisotope measurement and identification capability for special nuclear material.
\end{abstract}

\section{INTRODUCTION}

The Portable Isotopic Neutron Spectroscopy System (PINS) was developed for nondestructive evaluation of suspect chemical warfare material. ${ }^{1,2}$ PINS performs its evaluation by neutron activation analysis. A high purity germanium (HPGe) crystal is used to detect characteristic gamma rays. A software package makes a determination about what chemical weapon or explosive material is present.

The Field Radionuclide Identification System (FRIS) was developed independently to identify any radioactive material. ${ }^{3}$ FRIS uses an electromechanically cooled germanium detector (EMC HPGe) to detect passive $\gamma$-ray emissions. The EMC HPGe detector makes the system completely portable for long periods of time and significantly easier to deploy than systems which use liquid-nitrogen cooled germanium detector technology. The software associated with FRIS is a general purpose software identification package that has been tested extensively with liquid-nitrogen cooled germanium detectors. ${ }^{4}$ Both the PINS and FRIS systems require the high-resolution $\gamma$-ray spectroscopy that is possible with high purity germanium detectors.

Both systems have been successfully field tested, and PINS has been extensively used for munitions identification. ${ }^{5,6}$ The two systems can be combined to provide a complete general radioisotope, special nuclear material, and chemical weapons/explosives detection and identification system. The final system will consist of the EMC HPGe detector and one software package for data analysis.

\section{DESCRIPTION OF THE TWO SYSTEMS: A. PINS}

Neutrons from a radioisotopic ${ }^{252} \mathrm{Cf}$ source or from an ion tube neutron source ${ }^{7}$ are used to interrogate the contents of chemical weapons, explosives or a munition. Neutrons pass through the container material and are captured or scattered by the nucleus of one of the chemical elements within the munition.

Capture reactions $(n, \gamma)$ and inelastic scattering reactions $\left(n, n^{\prime} \gamma\right)$ take place within the nuclei of the atoms that make up the chemical weapons material. The nuclei then emit high-energy gamma rays which are characteristic of the chemical element. A high-purity germanium (HPGe) detector detects gamma rays. Fig. 1 shows a good measurement setup, including the ${ }^{252} \mathrm{Cf}$ source, tungsten shadow blocks, the $\gamma$-ray collimator, and the HPGe detector.

The PINS system can identify the fills of most munitions in 1000 seconds or less, depending on the fill and size of the munition. PINS sensitivity is the highest for the various smoke fills, followed by the $\mathrm{CW}$ agents that contain chlorine, and then by the CW agents that contain phosphorus. PINS is least sensitive to explosivefilled items because of the relatively low neutron cross section of nitrogen.

The PINS software rechecks the energy calibration, identifies all of the $\gamma$-ray peaks in the 


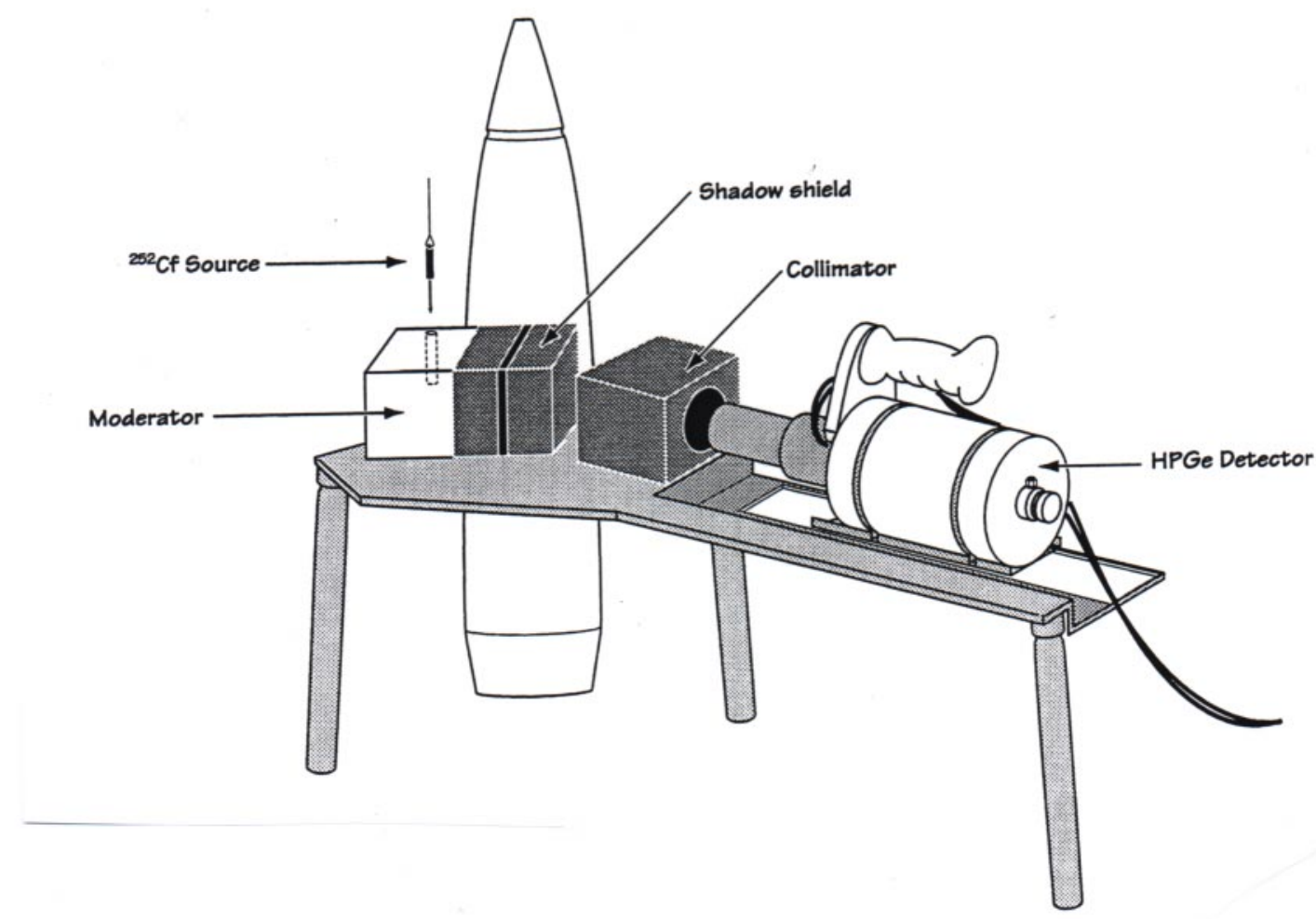

Figure 1. Experimental measurement setup for the PINS system. The ${ }^{252} \mathrm{Cf}$ source emits neutrons, which penetrate the container to illuminate the chemical weapon material. Tungsten shadow blocks protect the germanium detector from direct exposure to neutrons.

spectrum, and determines which chemical elements are present. The relative abundances of the chemical elements in the material are determined by the relative peak intensities associated with each $\gamma$-ray line. The PINS software then executes a decision-tree logic pathway to determine the item's fill.

\section{B. FRIS}

The FRIS system, which couples the electromechanically cooled detector with general purpose $\gamma$-ray analysis software, was originally developed for US Customs to provide the ability to rapidly differentiate between special nuclear material and other radioactive materials being transported through U.S. ports of entry. The system is compact, portable, and capable of battery operation.

The electromechanically cooled detector is a self-calibrating, active-vibration-controlled electromechanical cooler coupled to a high purity germanium detector. It is the activevibration control system that reduces the vibration to tolerable levels. ${ }^{8}$

The control system for FRIS operates on a Windows platform with a Visual Basic user interface. The time to process the data and to identify the radioisotopes is dependent on the strength of the source, distance between source and detector, and whether any shielding is present. For average sized sources found in standard field scenarios, 30 seconds is sufficient for data collection followed by a short time (5 10 seconds) to perform the analysis. The user interface reports either special nuclear material, industrial, medical radioisotopes, or "nothing to report." The user can click on any of these for further information regarding specific isotopes and confidence of reporting.

\section{DATA}

The first step in the integration of the PINS/FRIS systems was to verify that the electromechanically cooled detector would take data with sufficient resolution so that the PINS software could analyze that data. Introduction of the electromechanically cooled detector into the PINS system allows freedom from the requirements of liquid nitrogen. Measurements were made with mustard gas (HD) simulant. The experimental setup was the same as shown in Fig. 1 but with the EMC HPGe detector. For this test, the EMC HPGe detector was a 74\% detector 
with resolution of $2.5 \mathrm{keV}$ at $1332 \mathrm{keV}\left({ }^{60} \mathrm{Co}\right)$. Measurements with a LN cooled detector were made on the same day to insure a fair comparison. The LN cooled detector used was a $52 \%$ detector and had a $2.4 \mathrm{keV}$ energy resolution at $1332 \mathrm{keV}$. The measurements were made with about $40 \%$ dead time, and data were collected for a total live time of 1000 seconds.

Figs. 2 and 3 and show the results of the $\gamma$-ray energy spectra for the mustard gas simulant collected with both detectors. Fig. 2 shows the $900-1400 \mathrm{keV}$ energy range and Fig. 3 shows the $1700-2300 \mathrm{keV}$ energy range. The only noticeable difference between the spectra collected with the two detectors is that the peakto-background ratio is better for the LN cooled detector. The PINS software package correctly identified mustard gas for both tests.

As described in Figs. 2 and 3, the spectra clearly show the presence of chlorine and hydrogen, as well as aluminum, iron and silicon. Of particular interest in the identification of mustard gas are the chlorine peaks at 1164,1950 and $1959 \mathrm{keV}$, and the hydrogen peak at 2223 $\mathrm{keV}$.
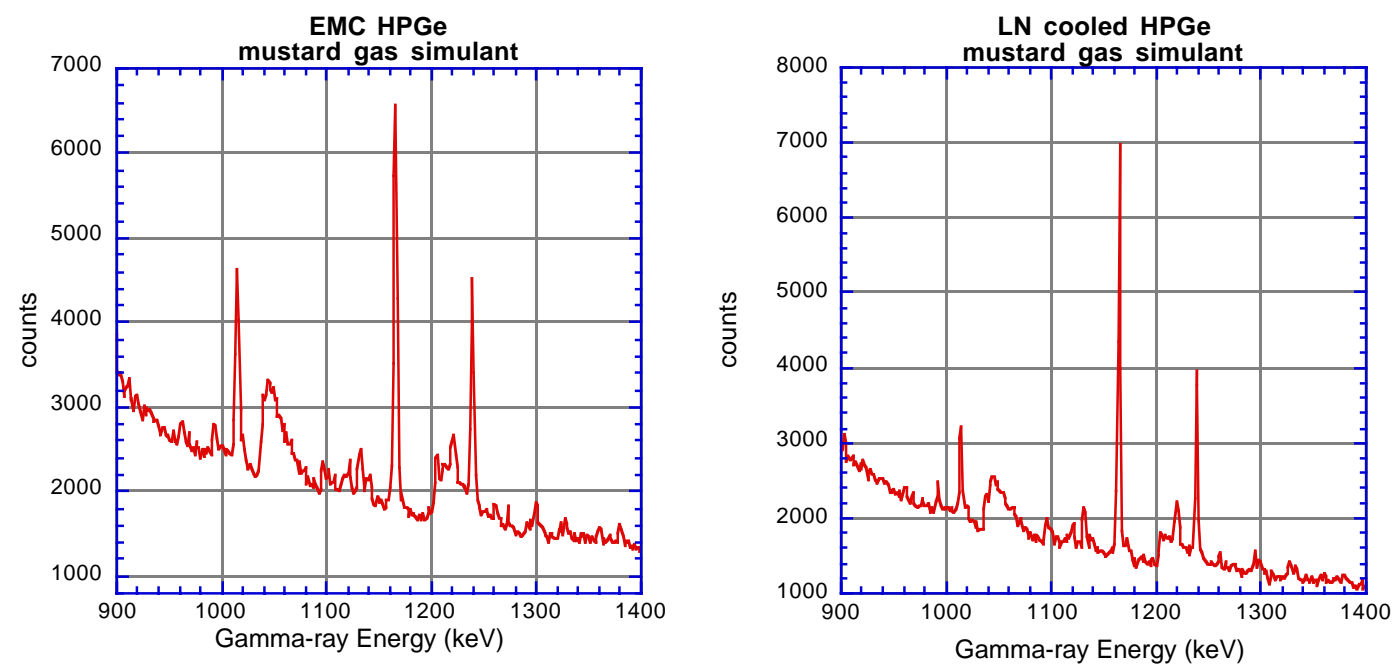

Figure 2. Mustard gas simulant from $900-1400 \mathrm{keV}$ detected by the electromechanically cooled HPGe detector (left) and the LN cooled HPGe detector (right). The $\mathrm{Al}$ peak at $1014 \mathrm{keV}$ is clearly seen, as is the Ge peak at $1039 \mathrm{keV}, \mathrm{Cl}$ at $1164 \mathrm{keV}$, and $\mathrm{Fe}$ at $1238 \mathrm{keV}$.
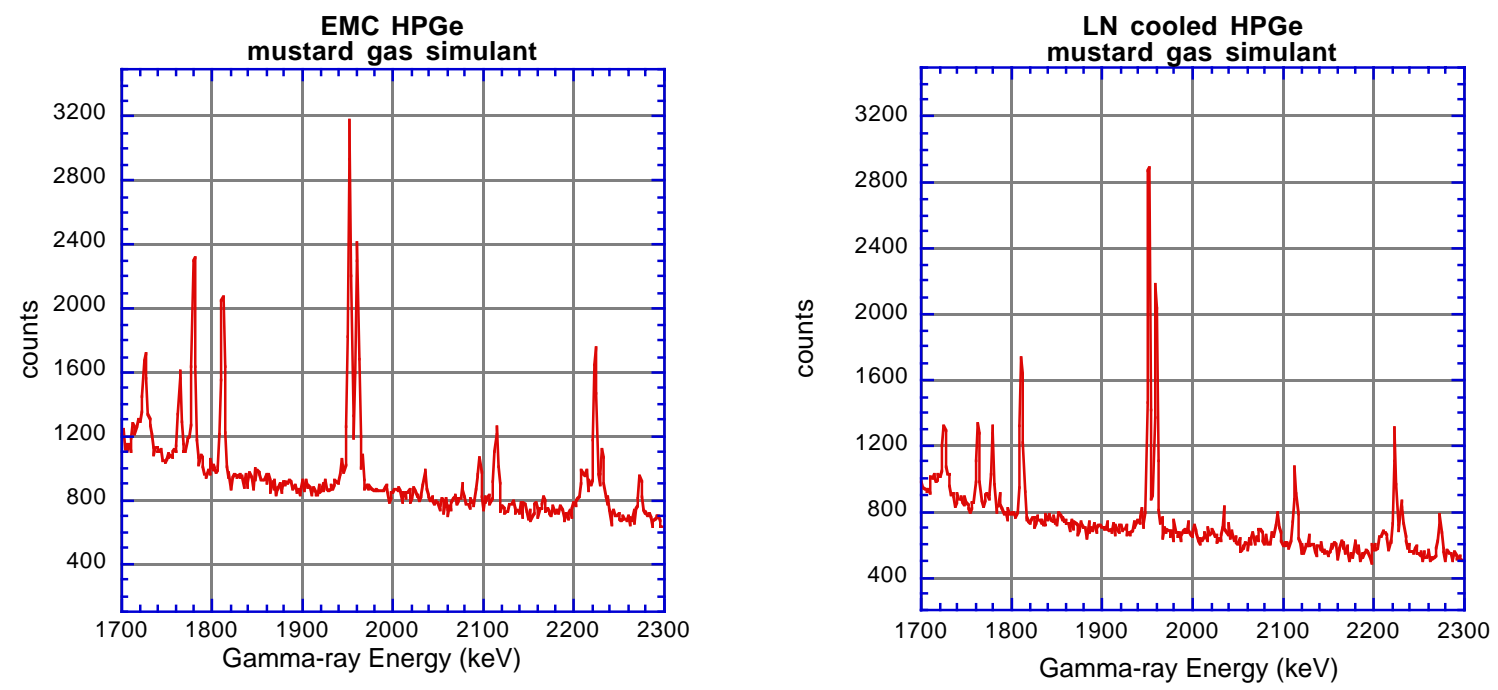

Figure 3. Mustard gas simulant in the $1700-2300 \mathrm{keV}$ energy range detected by the EMC HPGe detector (left) and the liquid-nitrogen cooled HPGe detector (right). A Si peak can be seen at $1779 \mathrm{keV}, \mathrm{Fe}$ at $1811 \mathrm{keV}, \mathrm{Cl}$ at 1950 and $1959 \mathrm{keV}, \mathrm{Fe}$ at $2113 \mathrm{keV}$, and $\mathrm{H}$ at $2223 \mathrm{keV}$. 


\section{DISCUSSION}

Our preliminary measurements indicate that the energy resolution of the electromechanically cooled germanium detector is sufficient for the PINS software to correctly analyze data. Our next set of tests will include explosives, and actual chemical agents instead of simulants.

We will then evaluate further integration of FRIS and PINS by selecting a software package that will analyze both the $\gamma$-ray data from radioactive material as well as the neutron induced radioactivity in PINS. One possibility is to use the current FRIS software for both chemical weapons/explosives and radioactive material identification. This will involve the development of an appropriate library and verification of the proper and adequate analysis of the $(n, \gamma)$ and $\left(n, n^{\prime} \gamma\right)$ lines used in the PINS analysis.

There are several additional features which would be desirable for the PINS/FRIS hybrid instrument. These modifications would improve its applicability for counter-terrorism applications. They are not required for the instrument to work, but would be most helpful for operation by personnel who do not have extensive detector technology training. Additional modifications would include automated hardware setup and simplified operation of the software. For the simplified operation of the software, we need to develop a software shell with a graphical user interface to facilitate PINS/FRIS selection and to perform a set of operational checks and verifications. These operational checks can include: absorber, collimator, and shielding verification, as well as a check of neutron source presence or absence.

\section{ACKNOWLEDGEMENTS}

This work was performed under the auspices of the U.S. Department of Energy by Lawrence Livermore National Laboratory under Contract No. W-7405-Eng-48.

\section{REFERENCES}

1. A. J. Caffrey, J. D. Cole, R. J. Greenwood, IEEE Transactions on Nuclear Science, 39, 1422 (1992).

2. A. J. Caffrey, B. D. Harlow, J. K. Hartwell, K. M. Krebs, G. D. McLaughlin, and A. L. Siedenstrang, "PINS Chemical Assay System Accuracy for Field-Recovered Munitions and Containers," Idaho National Engineering and Environmental Laboratory, INEEL/EXT-98-00218, April 1998.

3. G. J. Mauger, "Electromechanically Cooled High Purity Germanium Spectrometer System," p. 8 in the Lawrence Livermore National Laboratory Safeguards and Security Quarterly Progress Report to the U.S. Department of Energy, UCRL-ID106454-99-1, January 1999.

4. R. Gunnink and J. B. Niday, "Computerized Quantitative Analysis By Gamma-Ray Spectrometry, Vol. I. Description of the GAMANAL Program," Lawrence Livermore National Laboratory, UCRL-51061, 1971.

5. A. L. Siedenstrang, G. D. McLaughlin, K. M. Krebs, J. K. Hartwell, R. J. Gehrke, and A. J. Caffrey, "PINS Chemical Assay System User's Manual," Idaho National Engineering and Environmental Laboratory, EG\&G-PHY-10389, April 1994.

6. A. J. Caffrey, R. J. Gehrke, R. C. Greenwood, J. K. Hartwell, K. M. Krebs, G. D. McLaughlin, A. L. Siedenstrang, and K. D. Watts, "U.S. Army Experience with the PINS Chemical Assay System," Idaho National Engineering and Environmental Laboratory, EGG-NRP-11443, September 1994.

7. R. A. Alvarez, A. D. Dougan, M. R. Rowland, T.-F. Wang, J. of Radioanal. and Nucl. Chem., Articles, 192, 73 (1995).

8. G. J. Mauger, W. E. Parker, B. B. Bandong, R. G. Lanier, and A. D. Lavietes, Proceedings of SPIE, "Penetrating Systems and Applications," F. P. Doty, Ed., pp. 43-50, Denver, Colorado, July, 1999. 